\title{
İlk ve Acil Yardım Programında Okuyan Öğrencilere Ambulans Simülasyon Laboratuvarında Uygulanan Eğitimin Temel Beceri Düzeyine Etkisi
}

\section{The Effect of Essential Skills of Ambulance Simulation Laboratory Education to the First Aid and Emergency Program's Students}

\author{
Deniz ÖZTÜRK, ${ }^{\mathrm{a}}$ Ayşe GÜROL, ${ }^{\mathrm{b}}$ Seval USLU, ${ }^{\mathrm{c}}$ Osman YÜCEL ${ }^{\mathrm{d}}$
}

\begin{abstract}
ÖZET Amaç: Bu çalışma Sağlık Hizmetleri Meslek Yüksekokulu İlk ve Acil Yardım programında okuyan öğrenciler üzerinde ambulans simülasyon laboratuvarında uygulanan eğitimin beceri düzeyine etkisini incelemek amacıyla yapıldı. Gereç ve Yöntem: Yarı deneme modelinde gerçekleştirilen çalışmaya 2013-2014 öğretim yılında Sağlık Hizmetleri Meslek Yüksekokulu İlk ve Acil Yardım programı birinci sınıfta okuyan 67 öğrenci alındı. Veri toplama aracı olarak, araştırmacılar tarafından hazırlanan, öğrencilerin tanımlayıcı özelliklerini içeren soru formu ve "Beceri Değerlendirme Formu" kullanıldı. Öğrencilerin simülasyon eğitimi öncesi ve sonrasında ambulans içerisinde hastaya müdahale amaçlı yaptıkları temel tıbbi girişimleri ile ilgili beceri düzeyleri, simülasyon uygulamaları öncesinde ve sonrasında "Beceri Değerlendirme Formu" üzerinden değerlendirildi. Simülasyon uygulamaları tekrarlayan aralıklarla üç kez ve öğretim elemanı gözetiminde yapıldı. Bulgular: Çalışmaya katılan öğrencilerin \%61.2'si kı, \%38.8'i erkek, yaş ortalaması $18.67 \pm 1.18$ yıl idi. Öğrencilerin \%85.1'i sağlık meslek lisesi mezunu olduğunu, \%40.3'ü bir kurumda çalışmakta olduğunu ve çalışan öğrencilerin \%40.7'si 112'de \%14.8'i hastanede acil tıp teknisyeni olarak çalıştığını belirtti. Öğrencilerin simülasyon öncesi ve sonrası "Soluk yolunu açma" ve "Kalp masajını uygulama" işlem basamaklarını doğru yapma oranları karşılaştırıldığında aralarındaki farkın istatistiksel olarak ileri derecede anlamlı olduğu, simülasyon sonrası işlem basamaklarını daha doğru yaptıkları bulunmuştur $(\mathrm{p}<0.001)$. Sonuç: Öğrencilerin temel yaşam desteği uygulamalarına yönelik işlem basamaklarının hepsinde doğru yapma oranları simülasyon eğitimi sonrasında artmıştır. Sonuç olarak simülasyonla eğitimin öğrencilerin beceri düzeylerini artırdığı söylenebilir.
\end{abstract}

Anahtar Kelimeler: Beceri, eğitim, simülasyon, temel yaşam desteği uygulamaları

ABSTRACT Aim: This study has been performed to evaluate the effect of the applied-education in the ambulance simulation laboratory on the skill level of students registered in the Emergency and First Aid Program of Health Services Vocational School. Material and Methods: 67 students, registered in junior class of the Emergency and First Aid Program of Health Services Vocational School in 2013-2014 academic year, were admitted to the study conducted with half experimental model. Student questionnaires and "Skills Assessment Form" prepared by researchers which contained descriptive features of students were used as the data collection tool. Basic skill levels of students, related to the intervention for the patient in the ambulance, were evaluated pre and post-simulation education using the "Skills Assessment Form". Simulation applications were performed under the supervision of the instructor with repeated intervals. Results: Female percentage were $61.2 \%$, male percentage were $38.8 \%$ and the mean age were about $18.67 \pm 1.18$ for the students participated in the study. $85.1 \%$ of the students were the health vocational high school graduates, percentage of the working students and employees in an institution were $40.3 \%$. $40.7 \%$ of working students were employed in 112 and $14.8 \%$ were employed as emergency medical technician in a hospital. When pre and post-education performances of students in "opening the pale road" and "Heart massage application" were compared it was found that the difference was statistically significant $(p<0.001)$ and they performed the operation steps more accurately after the education. Conclusion: Accuracy of performing the basic life support applications of students were improved in all steps following the simulation education. As a result, it can be concluded that skill levels of students have been increased due to the education with simulation.

Key Words: Skill, education, simulation, basic life support applications

\section{Giriş}

Simülasyon, gerçekte var olan görevlerin, davranışların ya da bazı bilişsel aktivitelerin ilişkilerin, fenomenlerin, ekipmanların, taklit edilmesi olarak tanımlanmaktadır. ${ }^{1}$

Geliş Tarihi/Received: 18-02-2016/ Kabul Tarihi/Accepted: 19-11-2016

a Yrd. Doç. Dr. Atatürk Üniversitesi, Sağlık Hizmetleri Meslek Yüksekokulu, Erzurum, d.ozturk@atauni.edu.tr b Doç. Dr. Atatürk Üniversitesi, Sağlık Hizmetleri Meslek Yüksekokulu, Erzurum, gurola@atauni.edu.tr c Okutman. Atatürk Üniversitesi, Sağlık Hizmetleri Meslek Yüksekokulu, Erzurum, suslu@atauni.edu.tr d Yrd. Doç. Dr. Atatürk Üniversitesi, Sağllk Hizmetleri Meslek Yüksekokulu, Erzurum, oyucel@atauni.edu.tr Sorumlu yazar /correspondence: Doç. Dr. Ayşe GÜROL, Atatürk Üniversitesi, Sağlık Hizmetleri Meslek Yüksekokulu, 25030 Kampüs/Erzurum, ayseparlak42@gmail.com 
Simülasyon, öğrencilerin bir rehber öncülüğünde gerçek bir ortamı önceden deneyimlemesini sağlayan bir tekniktir., ${ }^{2,3}$ Bradley, sağlık eğitiminde simülasyon yöntemini geniş bir bakış açısı ile ele almış ve sadece teknolojik bilgisayar imkanları olarak değil, aynı zamanda önemli derecede insan etkileşimini içeren bir eğitim yelpazesi olarak ifade etmiştir. ${ }^{4}$

Temel sağlık eğitimi açısından, anatomi, fizyoloji, biyokimya gibi çeşitli temel bilimlerin eğitiminde simülasyon uygulamalarından yararlanılmaktadır. ${ }^{5}$ Simülasyon gerçekte var olan tüm olası durumları taklit edebilmeli, öğrencinin gerçeğe uygun şekilde cevap verebileceği zengin bir ortam sağlamalıdır. ${ }^{6,7}$

Simülasyona dayalı eğitim ile düzenli olarak geri bildirimlerin verilmesi ve sağlanan sürekli tekrarlar öğrencinin performansını ve kendine güvenini artırmaktadır. ${ }^{8-12}$ Öğrenciler açısından yaptıkları pratik uygulamanın fazla olması anksiyetelerinin azalmasını sağlayarak özgüvenlerinin geliştirmekte ve yaptıkları işin kalitesini artırmaktadır. ${ }^{13,14}$ Simülasyon eğitimi ile öğrenciler; hastanın mevcut durumunu anlama veya başarısızlık korkusu olmaksızın, güvenli bir ortamda tam bir bakım uygulama yeteneği, teknik beceri, karar verme, değerlendirme, ekip çalışması ve yönetim becerisi kazanmaktadır., Simülasyon uygulamaları kullanılarak yapılan sağlık personeli eğitimi, öğrencilere mesleki bilgi yanında bu bilgileri uygulama alanına aktarabilme becerisi de kazandırmalıdır. ${ }^{16} \mathrm{Bu}$ anlamda Resusitasyon ve Travma dersleri bilimsel temellere dayalı bilgi, beceri ve davranışların öğrencilere öğretildiği mesleki derslerdir. ${ }^{17}$

$\mathrm{Bu}$ bilgiler 1 șı̆̆ında araştırma, bir üniversitenin İlk ve Acil Yardım programının örgün ve ikinci öğretiminde 1. sinıfta okuyan, Resusitasyon ve Travma derslerini alan öğrencilerin, bu derslerde kazanmaları gereken temel tıbbi girişimleri, ambulans simülasyon çalışmaları ile öğrencilerin beceri düzeyine olan etkilerinin değerlendirilmesi açısından incelenmesi amacıyla gerçekleştirildi.

\section{Gereç ve Yöntem}

Araştırma, yarı-deneme modelinde tasarlandı. Araştırmanın evrenini 2013-2014 eğitim-öğretim y1lı bahar döneminde bir üniversitenin Sağlık Hizmetleri Meslek Yüksekokulu İlk ve Acil Yardım programında öğrenim gören, birinci sinifta olan ve Resusitasyon ve Travma derslerini alan 67 öğrenci oluşturdu. Araştırmada örneklem seçimine gidilmedi. İlgili dersleri alan ve çalışmaya katılmayı kabul eden bütün öğrenciler araştırmaya dahil edildi.

Çalışmaya başlamadan önce öğrencilere araştırmanın amacı açıkland, veri toplama araçları hakkında bilgi verildi. Araştırmaya katılmaya gönüllü olanlardan sözlü ve yazılı onam alındı. Araştırmanın yürütülebilmesi için Sağllk Hizmetleri Meslek Yüksekokulu Müdürlüğü'nden yazılı izin alındı.

Verilerin toplanmasında, öğrencilerin tanımlayıcı özelliklerini içeren soru formu ve beceri değerlendirme formu kullanıldı. $\mathrm{Bu}$ formlar;

Öğrencilerin Tanımlayıcı Özelliklerini Içeren Soru Formu: Öğrencilerin cinsiyeti, yaş1, sağlık çalışanı olmayı isteme durumu, daha önce hasta bakım sorumluluğu alma durumu, okul öncesi hastane deneyimi yaşama durumunu sorgulayan sorulardan oluşmaktadır.

Beceri Değerlendirme Formu: Araştırmacılar tarafindan geliştirilen form öğrencinin maket üzerinde yaptığı her bir uygulamayı doğru yapıp yapmadığının simülasyon öncesi ve sonrası değerlendirilmesini sağlamaktadır.

Veri toplama araçları, "Resusitasyon ve Travma” derslerinde, soluk yolunu açma, ekspirasyon havasıyla yetişkin kişiye suni solunum uygulama, kalp masaj1 uygulama konusu teorik olarak anlatıldıktan sonra ve laboratuar ortamında öğretim elemanı gözetiminde üç (3) simülasyon denemesi yapıldıktan sonra uyguland1. Teorik bilgiler öğrencilere dersin işlendiği sınıf ortamında anlatıldı. Öğrencilere simülasyon uygulamaları laboratuar ortamında gösterildi. Öğrencilere her bir uygulamanın teorik bilgileri anlatıldıktan sonra, öğretim elemanı gözetiminde her bir uygulamaya firsat veren özel maketler üzerinde üçer kez denemeleri sağlandı. Öğrencilerin bütün uygulamaları aynı öğretim elemanı gözetiminde, anlatılan her bir teorik dersin laboratuar saatinde, her gün bir deneme yaparak, haftada üç gün üst üste uygulamaları sağlandı. Uygulama öncesi öğrencilerin beceri düzeyleri "yaptı" "yapmadı" şeklinde değerlendirildi ve pre test olarak kabul edildi. Her gün sonunda simülasyon eğitimi sonrası öğrencilerin yapmakta zorlandıkları uygulamalar tekrar anlatıldı. Öğrencilerin üçüncü gün son denemelerinden sonraki beceri kontrol listesinde uygulamanın değerlendirilmesi son test olarak kabul edildi. Öğrencilerin ilk uygulama öncesi aldıkları ve üçüncü gün sonunda aldıkları değerlendirmeler karşılaştırıldı. 
Verilerin

kodlanmas

ve değerlendirilmesi bilgisayar ortamında SPSS 20.0 paket programında yapıldı. Önemlilik düzeyi $\mathrm{p}<0.05$ olarak alındı. Verilerin değerlendirilmesinde; öğrencilerin tanımlayıcı özellikleri yüzdelik dağılım, öğrencilerin eğitim öncesi ve eğitim sonrası işlem basamaklarını doğru yapma oranlarının karşılaştırılmasında kare testi $\left(\mathrm{X}^{2}\right)$ kullanıldı.

\section{Bulgular}

Çalışmaya katılan öğrencilerin \%61.2'si kız, \%38.8'i erkek, yaş ortalaması $18.67 \pm 1.18$ yıl idi. Çalışmaya katılan öğrencilerin çoğunluğu (\%98.5) sağlık personeli olmayı istemiş olduğunu ve okudukları bölümün kendi tercihleri olduğunu bildirdi. Öğrencilerin \%85.1'i sağlık meslek lisesi mezunu olduğunu ve bu öğrencilerin \%68.7'si İlk ve Acil Yardım programında okuduğunu ve bu öğrencilerin hepsi daha önce Resusitasyon ve Travma derslerini aldığını bildirdi. Öğrencilerin \%40.3'ü bir kurumda çalışmakta olduğunu ve çalışan öğrencilerin \%40.7'si 112'de \%14.8'i hastanede acil tıp teknisyeni olarak çalıştığını belirtti.

Araştırma kapsamına alınan öğrencilerin eğitim öncesi ve sonrası soluk yolunu açma işlem basamaklarını doğru yapma oranlarının karşılaştırılması Tablo 1'de verildi. Öğrencilerin bütün işlem basamaklarını doğru yapma oranlarının eğitim öncesine göre arttığ 1 ve aralarındaki farkın istatistiksel olarak ileri derecede anlamlı olduğu görüldü $(\mathrm{p}<0.001)$.

Tablo 1. Öğrencilerinin Simülasyon Eğitimi Öncesi ve Sonrası Soluk Yolunu Açma İşlem Basamaklarını Doğru Yapma Oranlarının Karşılaştırması

\begin{tabular}{|c|c|c|c|c|c|c|}
\hline & \multirow{2}{*}{ İşlem Basamakları } & \multicolumn{2}{|c|}{ Eğitim Öncesi } & \multicolumn{2}{|c|}{ Eğitim Sonras1 } & \multirow{2}{*}{$\mathrm{p}$ değeri } \\
\hline & & Say1 & $\%$ & Say1 & $\%$ & \\
\hline 1. & $\begin{array}{l}\text { Soluk almada zorlanan oturur haldeki hastanın, düz bir } \\
\text { zemine veya sedyeye sırt üstü yatırılması/ Yatar } \\
\text { haldeki hastanın, başının yastık veya yükseltici varsa } \\
\text { bunların alınması }\end{array}$ & 25 & 37.3 & 67 & 100 & $\mathrm{p}<0.001$ \\
\hline 2. & $\begin{array}{l}\text { Bir el hastanın alnına yerleştirilirken, diğer el ile ense } \\
\text { desteklenerek başın geriye yatırılması }\end{array}$ & 25 & 37.3 & 67 & 100 & $\mathrm{p}<0.001$ \\
\hline 3. & $\begin{array}{l}\text { Bir el ile hastanın alnı desteklenirken ensedeki elin alt } \\
\text { çeneye getirilmesi }\end{array}$ & 25 & 37.3 & 67 & 100 & $\mathrm{p}<0.001$ \\
\hline 4. & $\begin{array}{l}\text { Alt çenedeki elin parmak uçları ile alt çenenin } \\
\text { desteklenmesi }\end{array}$ & 25 & 37.3 & 67 & 100 & $\mathrm{p}<0.001$ \\
\hline 5. & $\begin{array}{l}\text { Alt dişler ile üst dişler aynı hizaya gelene kadar, alt } \\
\text { çenenin öne ve yukarı doğru hareket ettirilmesi }\end{array}$ & 25 & 37.3 & 67 & 100 & $\mathrm{p}<0.001$ \\
\hline 6. & $\begin{array}{l}\text { Angulus mandibula ile çene çıkıntısı arasında kalan alt } \\
\text { çene kemiğinin düz kısmı, yere dik açı oluşturana } \\
\text { kadar çenenin yukarı doğru kaldırılması ve başın } \\
\text { geriye doğru yatırılması }\end{array}$ & 25 & 37.3 & 67 & 100 & $\mathrm{p}<0.001$ \\
\hline \multirow[t]{2}{*}{7.} & $\begin{array}{l}\text { Hastanın ağzının açıklığını sağlamak üzere, baş } \\
\text { parmakla hastanın alt çenesinin geriye (öne) doğru } \\
\text { çekilmesi }\end{array}$ & 25 & 37.3 & 67 & 100 & $\mathrm{p}<0.001$ \\
\hline & Travma Olasılığında veya Varlığında & & & & & \\
\hline 1. & $\begin{array}{l}\text { Baş1-boynu ve omurgası korunarak, hastanın sırt üstü } \\
\text { yatırılması }\end{array}$ & 11 & 16.4 & 67 & 100 & $\mathrm{p}<0.001$ \\
\hline 2. & $\begin{array}{l}\text { Hastanın baş kısmına diz çökerek, dirseklerin yere } \\
\text { dayanması }\end{array}$ & 11 & 16.4 & 67 & 100 & $\mathrm{p}<0.001$ \\
\hline 3. & $\begin{array}{l}\text { Dikkatli ve nazik hareketlerle ellerin hastanın alt } \\
\text { çenesine, kulak hizasındaki köşe çıkıntısına (angulus } \\
\text { mandibulaya) yerleştirilmesi }\end{array}$ & 11 & 16.4 & 67 & 100 & $\mathrm{p}<0.001$ \\
\hline 4. & Hastanın başının ön kollarda desteklenmesi & 11 & 16.4 & 67 & 100 & $\mathrm{p}<0.001$ \\
\hline 5. & $\begin{array}{l}\text { İç kısmındaki parmaklar kullanılarak, alt çenenin } \\
\text { köşelerden öne doğru itilmesi }\end{array}$ & 11 & 16.4 & 67 & 100 & $\mathrm{p}<0.001$ \\
\hline 6. & $\begin{array}{l}\text { Baş parmakla hastanın alt dudağı dışa doğru çekilerek, } \\
\text { ağZın açıklığının sağlanması }\end{array}$ & 11 & 16.4 & 67 & 100 & $\mathrm{p}<0.001$ \\
\hline
\end{tabular}

Öğrencilerinin simülasyon eğitimi öncesi ve sonrası erişkin kişiye ekspirasyon havasıyla suni solunum uygulama işlem basamaklarını doğru yapma oranlarının karşılaştırması incelendiğinde; bütün işlem basamaklarını doğru yapma oranlarının eğitim öncesine göre arttığı ve aralarındaki farkın istatistiksel olarak ileri derecede anlamlı olduğu görüldü $(\mathrm{p}<0.001$; Tablo-2). 


\begin{tabular}{|c|c|c|c|c|c|c|}
\hline & \multirow{2}{*}{ İşlem Basamakları } & \multicolumn{2}{|c|}{ Ĕ̆itim Öncesi } & \multicolumn{2}{|c|}{ Eğitim Sonrası } & \multirow{2}{*}{$\mathrm{p}$ değeri } \\
\hline & & Say1 & $\%$ & Say1 & $\%$ & \\
\hline 1. & Malzemelerin doğru ve eksiksiz hazırlanması & 28 & 41.8 & 67 & 100 & $\mathrm{p}<0.001$ \\
\hline 2. & $\begin{array}{l}\text { Hastanın yan tarafinda omuzları hizasında } \\
\text { durulması }\end{array}$ & 28 & 41.8 & 67 & 100 & $\mathrm{p}<0.001$ \\
\hline 3. & $\begin{array}{l}\text { Başucuna yakın olan el, hastanın alnına } \\
\text { yerleştirilmesi }\end{array}$ & 28 & 41.8 & 67 & 100 & $\mathrm{p}<0.001$ \\
\hline 4. & $\begin{array}{l}\text { Alındaki elin baş ve işaret parmakları serbest } \\
\text { bırakılması }\end{array}$ & 28 & 41.8 & 67 & 100 & $\mathrm{p}<0.001$ \\
\hline 5. & $\begin{array}{l}\text { Diğer el ile, hastanın alt çenesi öne-yukarı doğru } \\
\text { çekilmesi }\end{array}$ & 28 & 41.8 & 67 & 100 & $\mathrm{p}<0.001$ \\
\hline 6. & $\begin{array}{l}\text { Alındaki elin, baş ve işaret parmaklarıyla, hastanın } \\
\text { burun delikleri kapatılması }\end{array}$ & 28 & 41.8 & 67 & 100 & $\mathrm{p}<0.001$ \\
\hline 7. & Derin nefes alınması & 28 & 41.8 & 67 & 100 & $\mathrm{p}<0.001$ \\
\hline 8. & $\begin{array}{l}\text { Hastanın dudakları kendi dudaklarınız arasına } \\
\text { alınması }\end{array}$ & 28 & 41.8 & 67 & 100 & $\mathrm{p}<0.001$ \\
\hline 9. & $\begin{array}{l}\text { Ekspirasyon havasıyla, hastanın ağzından 1.5-2.0 } \\
\text { sn. süreyle inspirasyon yaptırılması }\end{array}$ & 28 & 41.8 & 67 & 100 & $\mathrm{p}<0.001$ \\
\hline 10. & $\begin{array}{l}\text { İzleyen solunum için baş kaldırılır ve hastanın } \\
\text { göğüs kafesinin şişip şişmediği gözlenmesi }\end{array}$ & 28 & 41.8 & 67 & 100 & $\mathrm{p}<0.001$ \\
\hline 11. & $\begin{array}{lccc}\text { Hastanın } & 3.0-3.5 & \text { sn. } & \text { süreyle ekspirasyon } \\
\text { yapmasına izin verilmesi } & & \\
\end{array}$ & 28 & 41.8 & 67 & 100 & $\mathrm{p}<0.001$ \\
\hline & $\begin{array}{l}\text { 6-7-8-9-10-11. işlemleri, dakikada } 12 \text { kez olacak } \\
\text { şekilde tekrarlanması }\end{array}$ & 28 & 41.8 & 67 & 100 & $\mathrm{p}<0.001$ \\
\hline
\end{tabular}

Öğrencilerinin simülasyon eğitimi öncesi ve sonrası tek kişiyle erişkin kalp masajı uygulama işlem basamaklarını doğru yapma oranlarının karșılaștırması incelendiğinde; bütün işlem basamaklarını doğru yapma oranlarının eğitim öncesine göre arttığ 1 ve aralarındaki farkın istatistiksel olarak ileri derecede anlamlı olduğu görüldü ( $<<0.001$; Tablo 3$)$.

\section{Tartışma}

Sağlık çalışanı yetiştiren okullarda okuyan öğrenciler (hemşirelik, anestezi teknikeri, diyaliz teknikeri vs.) derslerde edindikleri bilgileri hastalar üzerinde tam ve eksiksiz uygulamak zorundadır. $\mathrm{Bu}$ zorunluluğun nedeni yaptıkları işin insan sağlığı ve hayatı ile ilgili olmasından kaynaklanmaktadır. Bu nedenle öğrenciler, hasta üzerinde uygulama yapmadan önce derslerde ögrendikleri teorik konuları mutlaka laboratuar uygulamalarında pekiştirmelidir. Psikomotor beceri; bir işin yapılması sırasında kullanılan, bilinçli zihinsel etkinliğin yönlendirdiği koordineli kas etkinlikleridir. Bilinçli bir zihinsel etkinlik için öğrencinin karşı karşıya kaldığı problemi nasıl çözmesi gerektiğini merak etmesi, öğrenmesi ve uygulaması gerekir. Hemşirelik eğitiminde psikomotor becerilerin öğrenildiği yer mesleksel beceri laboratuvarıdır. ${ }^{18,19}$ Mesleksel beceri laboratuvarı klinik uygulamaya benzer ortamlar sağlayarak öğrenciyi kliniğe hazırlar ve teori ile uygulamanın birleştirilmesine yardım eder. $^{20-23}$

Çalışmamızda yer alan öğrencilerin soluk yolu açma, ekspirasyon havasıyla suni solunum ve kalp masajı yapmaya yönelik işlem basamaklarının çoğunda doğru yapma oranlarının simülasyon eğitimi sonrasında arttığı belirlenmiştir. Sonuç olarak simülasyonla eğitimin öğrencilerin beceri düzeylerini artırdığı söylenebilir. 
Tablo 3. Öğrencilerinin simülasyon eğitimi öncesi ve sonrası tek kişiyle erişkin kalp masajı uygulama işlem basamaklarını doğru yapma oranlarının karşılaştırması

\begin{tabular}{|c|c|c|c|c|c|c|}
\hline & \multirow{2}{*}{ İşlem Basamakları } & \multicolumn{2}{|c|}{ Eğitim Öncesi } & \multicolumn{2}{|c|}{ Eğitim Sonras1 } & \multirow{2}{*}{ p değeri } \\
\hline & & Say1 & $\%$ & Say1 & $\%$ & \\
\hline 1. & Malzemelerin doğru ve eksiksiz hazırlanması & 27 & 40.3 & 67 & 100 & $\mathrm{p}<0.001$ \\
\hline 2. & Hastanın omuzları hizasında diz çökülmesi & 27 & 40.3 & 67 & 100 & $\mathrm{p}<0.001$ \\
\hline 3. & $\begin{array}{l}\text { Hastanın ayak ucuna doğru olan elin işaret ve orta } \\
\text { parmaklarıyla bulunduğunuz taraftaki arkus } \\
\text { kostarium alt ucundan başlayarak palpe edilmesi }\end{array}$ & 27 & 40.3 & 67 & 100 & $\mathrm{p}<0.001$ \\
\hline 4. & $\begin{array}{l}\text { Arkus kostarium palpe edilerek, yukarıya doğru } \\
\text { ilerlenir. Her iki arkus kostariumun birleştiği } \\
\text { noktada Ksifoid çıkıntıyı hissedilmesi }\end{array}$ & 27 & 40.3 & 67 & 100 & $\mathrm{p}<0.001$ \\
\hline 5. & $\begin{array}{l}\text { Orta parmak ksifoid çıkıntı üzerine, işaret parmağ1 } \\
\text { sternumla ksifoid çıkıntının birleştiği yere } \\
\text { konulması }\end{array}$ & 27 & 40.3 & 67 & 100 & $\mathrm{p}<0.001$ \\
\hline 6. & $\begin{array}{l}\text { Diğer elin topuk kısmı, hastanın orta hattında } \\
\text { olacak şekilde, bu iki parmağın yanına } \\
\text { yaklaştırılması. }\end{array}$ & 27 & 40.3 & 67 & 100 & $\mathrm{p}<0.001$ \\
\hline 7. & $\begin{array}{l}\text { Ksifoid çıkıntıyı bulmak için kullanılan el, sternum } \\
\text { alt yarısına yerleştirilen elin üzerine konulması }\end{array}$ & 27 & 40.3 & 67 & 100 & $\mathrm{p}<0.001$ \\
\hline 8. & $\begin{array}{l}\text { Yukarıdan aşağıya dik bir şekilde, dirsekler } \\
\text { bükülmeden sternumu } 4-5 \mathrm{~cm} \text {. çökertecek şekilde } \\
\text { kompresyum uygulanması }\end{array}$ & 27 & 40.3 & 67 & 100 & $\mathrm{p}<0.001$ \\
\hline 9. & $\begin{array}{l}\text { Eller sternum alt yarısı üzerinden kaldırılmadan } \\
\text { dekompresyum fazına geçilir. Kompresyum, } \\
\begin{array}{l}\text { dekompresyum sürelerinin } \\
\text { sağlanması }\end{array}\end{array}$ & 27 & 40.3 & 67 & 100 & $\mathrm{p}<0.001$ \\
\hline 10. & Dakikada 80-100 ritmik kompresyon uygulanması & 27 & 40.3 & 67 & 100 & $\mathrm{p}<0.001$ \\
\hline 11. & $\begin{array}{l}\text { Hastanın başını ekstansiyona getirip, alt çene } \\
\text { kemiğini öne doğru çekerek, soluk yolu açılır ve } 2 \\
\text { ventilasyon uygulanması }\end{array}$ & 28 & 41.8 & 67 & 100 & $\mathrm{p}<0.001$ \\
\hline 12. & $\begin{array}{l}15 \text { kalp masaji/2 suni solunum olacak şekilde } 4 \\
\text { siklus işlem gerçekleştirilmesi }\end{array}$ & 28 & 41.8 & 67 & 100 & $\mathrm{p}<0.001$ \\
\hline 13. & $\begin{array}{l}\text { A.Karotis'ten (en fazla } 5 \text { sn. süreyle) yeniden nabz1 } \\
\text { kontrol edilmesi }\end{array}$ & 28 & 41.8 & 67 & 100 & $\mathrm{p}<0.001$ \\
\hline 14. & $\begin{array}{l}\text { Nabz1 yoksa, CPR-a devam edilmesi (15 kalp } \\
\text { masajı, suni solunumu) }\end{array}$ & 28 & 41.8 & 67 & 100 & $\mathrm{p}<0.001$ \\
\hline
\end{tabular}

Literatürde yer alan çalışmalarda farklı bilim dalları ve alanlarda okuyan öğrenciler üzerinde simülasyon eğitiminin faydaları sınanmıştır. Goldenberg ve arkadaşları (2005) klinik öncesi uygulanan bilgisayarlı simülasyon eğitiminin kritik durumlarda karar verme ile kognitif, psikomotor, iletişim, tartışma ve ögretim becerilerinde artmaya neden olduğunu saptamıştır. ${ }^{24}$ Alinier ve arkadaşlarının (2006) hemşirelik 2. sınıf öğrencileri üzerinde yaptığ 1 çalışmada, bilgisayarlı simülasyon eğitimi alan öğrencilerin objektif olarak yapılandırılmış klinik değerlendirme testinden daha yüksek puan aldıkları saptanmıştır. ${ }^{25}$ Bremner ve arkadaşlarının (2006) öğrenci hemşirelerle yaptı̆̆ 1 çalı̧̧mada ise, öğrenciler bilgisayarlı simülatör ile verilen eğitimin hastayı fiziksel değerlendirme becerilerinde kendilerine olan güveni arttırdığını (\%61), iyi ve mükemmel bir deneyim sağladığı (\%91) ve hemşirelik eğitiminde zorunlu olması gerektiğini (\%68) ifade etmişlerdir. ${ }^{26}$ Bambini ve arkadaşları (2009) simülasyon eğitimi öncesi ve sonras1 112 öğrenci üzerinde postpartum ve yenidoğan hemşireliği için gerekli olan becerilerin değerlendirildiği çalışmalarında, eğitim sonrası öğrencilerin öz-yeterliliğin istatistiksel olarak anlamlı şekilde arttığını, vital bulguları $(\mathrm{p}<.01)$, solunum ( $\mathrm{p}<.01)$, fundus $(\mathrm{p}<.001)$, loşya $(\mathrm{p}<$ $.001)$ değerlendirme ve hasta eğitimi sağlama ( $p$ $<$.001) öz güvenlerinin arttığını bildirmiştir. ${ }^{27}$ Benzer şekilde Kameg ve arkadaşları (2010) simülasyon kullanımının öğrencilerin anksiyete düzeylerini azalttı̆̆ını ve öz yeterliliklerini artırdığını saptamıştır. ${ }^{28}$ Meyer ve arkadaşları (2011) 8 haftalık sömestr süresince simülasyon eğitimi alan öğrencilerin terapötik becerilerinin pozitif olarak etkilendiğini bildirmiştir 
$(\mathrm{p}=0.02) .{ }^{29}$ Terzioğlu ve arkadaşlarının (2012) yaptığı çalışmada, öğrenci hemşirelerin klinik öncesi hazırlıklarının yetersiz olduğu; klinik ortamda kendilerini yetersiz ve güvensiz hissettikleri, hastaların ve hemşirelerin öğrencilere güvenmediği ve uygulama yapmalarına izin vermediği, teorikte anlatılanlarla klinikte uygulananlar arasında farklılıkların olduğu belirlenmiştir. ${ }^{30}$ Thomas ve Mackey (2012) sömestr başında ve sonunda simülasyon eğitimi ile geleneksel eğitimin 24 lisans hemşirelik öğrencisinin öz güveni üzerinde etkisini inceledikleri çalışmada, simülasyon eğitimi alan öğrencilerin hasta durumunu belirti ve bulguları tanımlama $(\mathrm{p}=0.00)$, değerlendirme $(\mathrm{p}=0.00)$, müdahale etme yeteneğinin $(\mathrm{p}=0.00)$ sömestr sonrası istatistiksel olarak önemli derecede arttığını saptamıştır. ${ }^{31}$ Szpak ve Kameg (2013) simülasyon eğitiminin öğrencilerin anksiyete düzeylerini azalttığını belirlemiștir. ${ }^{32}$

\section{Sonuç}

Temel tıbbi işlemlerin maketler üzerinde yapılması ve daha sonra bu işlemlerin hastalar üzerinde uygulanması ile daha yetenekli sağlık personellerinin yetişeceği açıktır. Bunun sonucu olarak; tıbbi hatalar büyük oranda azalacak, iyi yetişmiş sağlik personelleri tarafından daha etkin bir sağl1k hizmeti verilecektir. Bu nedenle, eğitimin kalitesini artırmak için maketler etkin bir şekilde kullanılmalıdır. Acil durumlarda hastaya ilk müdahalede bulunacak olan İlk ve Acil Yardım programı öğrencilerinin hayati tehlikesi olan hastaya müdahaledeki becerisi büyük önem arz etmektedir. $\mathrm{Bu}$ nedenle çalışmanın sonuçları, bu öğrencilerin okullardaki eğitiminin simülasyon üzerinden devam ettirilmesini gerekli kılmaktadır.

\section{Teşekkür}

Çalışma, Atatürk Üniversitesi Bilimsel Araştırma Projeleri tarafindan 2013/062 numaral proje olarak desteklenmiştir.

\section{Kaynaklar}

1. Mıdık Ö, Kartal M. Simülasyona dayalı tıp eğitimi [Simulation-Based Medical Education]. Marmara Medical Journal 2010;23(3): 389-99.

2. Issenberg SB, Mc Gaghie WC, Petrusa ER, Gordan DL, Scalese RJ. Features and uses of high-fidelity medical simulations that lead to effective learning: A BEME systematic review. Medical Teacher 2005;27(1): 1028.
3. Gaba DM. The future of simulation in healthcare. Simulation in Healthcare 2007; (2): 126-35.

4. Bradley P. The history of simulation in medical education and possible future directions. Medical Education 2006;40(3): 254-62.

5. Langrana N, Burdea G, Ladeji J, Dinsmore M. Human Performance Using Virtual Reality Tumor Palpation Simulation. Computers \& Graphics 1997;21: 451-458.

6. Maran NJ, Glavin RJ. Low-to high-fidelity simulationa continuum of medical education. Medical Education 2003;37(1): 22-8.

7. Cant RP, Cooper SJ. Simulation-based learning in nurse education: systematic review. Journal of Advanced Nursing 2009;66(1): 3-15.

8. Alinier G. Nursing students' and lecturers' perspectives of objective structured clinical examination incorporating simulation. Nurse Education Today 2003;23(6): 419-26.

9. Cioffi J. Clinical simulations: development and validation. Nurse Education Today 2001;21(6): 477-86.

10. Moule P, Wilford A, Sales R, Lockyer L. Student experiences and mentor views of the use of simulation for learning. Nurse Education Today 2008;28(7): 790-97.

11. Morgan PJ, Cleave-Hogg D. Comparison between medical students' experience, confidence and competence. Medical Education 2002;36(6): 534-39.

12. Reilly A, Spratt C. The perceptions of undergraduate student nurses of high-fidelity simulation-based learning: A case report from the University of Tasmania. Nurse Education Today 2007;27(6): 542-50.

13. Karaöz S. Hemşirelikte klinik öğretime genel bir bakış ve etkin klinik öğretim için öneriler [General view of clinical education in nursing and recommendations for effective clinical education]. Hemşirelikte Araştırma ve Geliştirme Dergisi 2003;5(1): 15-21.

14. Rhodes M, Curran C. Use of the human patient simulator to teach clinical judgment skills in a baccalaureate nursing program. Computers, Informatics, Nursing 2005;23(5): 256-62.

15. Kathleen AK. Associate degree nursing students' perceptions of learning using a high-fidelity human patient simulator. Teaching and Learning in Nursing 2007;2(2): 46-52. 
16. Tel H, Tel H, Sabancıoğulları S. Hemşirelik birinci sınıf öğrencilerinin laboratuar uygulamasında birbirlerine intramüsküler enjeksiyon uygularken ve klinik uygulamanın ilk gününde anksiyete durumlar1 [The Anxiety Status Of First Year Students Of Nursing At The Intramuscular Injection Laboratory Practice To Each Other And The First Day Of Clinical Training]. Atatürk Üniversitesi Hemşirelik Yüksekokulu Dergisi 2004;7(1): 27-32.

17. Ulusoy MF. Nitelikli hemşirelik eğitimi için nitelikli uygulama ortamı. Hemşirelik-Ebelik Eğitimi ve Uygulamalarında Kalite Sempozyumu Kitab1, 1998. p.52-55.

18. Bradley P, Postlethwaite K. Setting up a clinical skills learning facility. Medical Education 2003;37: 6-13.

19. Jeffries PR, Rew S, Cramer J. A comparison of student centered versus traditional methods of teaching basic nursing skill in a learning laboratory. Nursing Education Perpectives 2002;23: 14-9.

20. Du Boulay C, Medway C. The clinical skills resource: a review of current practice. Medical Education 1999;33: 185-89.

21. Freeth D, Fry H. Nursing students' and tutors' perceptions of learning and teaching in a clinical skills centre. Nurse Education Today 2005;25: 272-82.

22. Keetsemang S, Mugarurwa J, Shahidi T, Maputhege M, Chipps J, Brysiewicz P. Student evaluation of a clinical self-study laboratory. Nurse Education in Practice 2008;8. 359-67.

23. Morgan R. Using clinical skills laboratories to promote theory-practice integration during first practice placement: an Irish perspective. Journal of Clinical Nursing 2006;15: 155-61.

24. Goldenberg D, Andrusyszyn MA, Iwasiw C. The effect of classroom simulation on nursing students'selfefficacy related to health teaching. Journal of Nursing Education 2005;44(7): 310-314.

25. Alinier G, Hunt B, Gordon R, Harwood C. Effectiveness of intermediate-fidelity simulation training technology in undergraduate nursing education. Journal Compilation 2006;54(3): 359-69.

26. Bremner MN, Aduddell K, Bennett DN, VanGeest JB. The use of human patient Simulator. Nurse Educator 2006;31(4): 170174.

27. Bambini D, Washburn J, Perkins R. Outcomes of clinical simulation for novice nursing students: Communication, confidence, clinical judgment. Nursing Education Research 2009;30(2): 79-82.

28. Kameg K, Howard VM, Clochesy J, Mitchell A, Suresky J. The impact of high fidelity human simulation on self-efficacy of communication skills. Issues in Mental Health Nursing 2010; 31(5): 315-323.

29. Meyer MN, Connors H, Hou Q, Gajewski B. The effect of simulation on clinical performance: A junior nursing student clinical comparison study. Simulation in Healthcare 2011;6(5): 269-277.

30. Terzioğlu F, Kapucu S, Özdemir L, Boztepe H, Duygulu S, Tuna Z, Akdemir N. Simülasyon Yöntemine İlişkin Hemşirelik Öğrencilerinin Görüşleri [Nursing Students' Opinions About Simulation Method]. Sağllk Bilimleri Fakültesi Hemşirelik Dergisi 2012;19(1): 16-23.

31. Thomas C, Mackey E. Influence of a Clinical Simulation Elective on Baccalaureate Nursing Student Clinical Confidence. Journal of Nursing Education 2012; 51(4): 236-239.

32. Szpak JL, Kameg KM. Simulation decreases nursing student anxiety prior to communication with mentally ill patients. Clinical Simulation in Nursing 2013;9(1): e13-e19. 